\title{
Good versus bad medical stoppages in boxing: Stopping a fight in time
}

\author{
N K Sethi, MD \\ Department of Neurology, New York Presbyterian Hospital, Weill Cornell Medical Center, New York, USA \\ Corresponding author: N K Sethi (sethinitinmd@hotmail.com)
}

Background: Professional boxing is a popular contact sport with a high risk for both acute and chronic traumatic brain injury (TBI). Although rare, many boxers have died in the ring or soon after the completion of a bout. The most common causes of death in these cases are usually acute subdural hematomas, acute epidural hematomas, a subarachnoid haemorrhage, an intracranial haemorrhage or Second Impact Syndrome (SIS). Ringside physicians are entrusted with the health and safety of boxers in the ring and in the immediate aftermath of a bout.

Discussion: As per the Uniform Boxing Rules (approved August 25, 2001, Amended August 2, 2002, Amended July 3 , 2008, Amended July 24, 2012, Amended July 29, 2014), the referee is the sole arbiter of a bout and is the only individual authorised to stop a contest. ${ }^{[1}$ In some states in the United States and in other countries around the world, the referee and the ringside physician are the sole arbiters of a fight and the only individuals authorised to enter the fighting area at any time during the competition and also authorised to stop a fight. This raises the important question of when should a fight be stopped on medical grounds.

Conclusion: Standardising medical stoppage decisions in boxing will help to protect a boxer's health and safety in the ring. Good practice guidelines for medical stoppage due to suspected TBI are suggested. It is recommended that the medical community debate the proposed guidelines vigorously, in order that evidence-based guidelines can be developed in conjunction with professional boxing governing bodies.

Keywords: safety, concussion, knockout, traumatic brain injury, contact sports

S Afr J Sports Med 2016;28(3):87-89.DOI:10.17159/2078-516X/2016/v28i3a1735

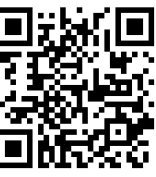

In the boxing fraternity it is commonly said and not without reason "...the fight must go on...".Everyone ringside wants the fight to continue - the two boxers and their corners (sometimes not always), the promoter (always), the media (always), the spectators (always), the Commission and its appointed officials (only if both the boxers meet the Commission requirements for a fair and honestly administered contest), the referee (only if the boxers are fighting a fair fight and able to defend themselves), the judges (usually do not interfere with the conduct of the fight) and the ringside physicians (only if the boxers are medically fit before, during and immediately after the contest).

As per the Uniform Boxing Rules (approved August 25, 2001, Amended August 2, 2002, Amended July 3, 2008, Amended July 24, 2012, Amended July 29, 2014), the referee is the sole arbiter of a bout and the only individual authorised to stop a contest. ${ }^{[1]}$ In some states in the United States and in other countries around the world, both the referee and ringside physician are the sole arbiters of a fight and the only ones authorised to enter the fighting area at any time during the competition and to stop a fight. The referee and the ringside physician's threshold to stop a fight may vary based on their knowledge of boxing rules and regulations, knowledge of the boxers' fitness level, pre-existing medical conditions, pre-bout fitness, intra-bout fitness and finally, knowledge of their medical condition and bout-ending injuries (for example, head injuries, orthopaedic injuries, eye injuries, blunt abdominal trauma). For these reasons it is the referee (someone who has knowledge of boxing rules and regulations) and the ringside physician (someone who has knowledge of medicine) who are deemed to be the sole arbiters of a bout and entrusted with the health and safety of the boxers. A most important question is when the fight should be stopped on medical grounds. Stopping a bout prematurely is unfair to the boxers, their corners, the promoters and the public. Stopping a bout too late may risk serious injury and even the possible death of the boxer.

Boxer safety should precede all other considerations. The goal should be to stop a bout before a life-threating injury or career-ending injury occurs. Since there are times when this is not possible, a more realistic goal should be the timely identification of a serious injury in the ring followed by the stoppage of the fight. It is therefore essential that the referee and the ringside physician work as a team, complimenting each other's knowledge. Causes of sudden death in the ring or in the immediate aftermath of a bout are usually neurological. ${ }^{[2]}$

In order to identify and prevent TBI in boxing, the following good practice guidelines are proposed based on personal and collective evidence of experienced ringside physicians and clinical acumen:

1. It is a good point to remember that boxers rarely, if ever, voluntarily quit or request that the fight be stopped. They fight for pride, at times at the expense of their health. Corners may also not want the fight to be stopped hoping that their boxer may turn things around. In a closely contested fight the crowd is excited and wants the fight to continue. This is when the ringside physician should stop the fight or let it continue, based solely on the medical condition of the boxer.

2. During the one-minute rest period between rounds, the ringside physician should step up to the ring for a quick but thorough medical evaluation of the fighter. This is the ideal time for the ringside physician to assess the neurological status of a fighter. 
3. In the case of a fighter who had suffered a knock-down in the preceding round or sustained multiple head shots, the ringside physician should conduct a quick visual evaluation of the fighter (Is the fighter responding appropriately to the commands and directions of his corner? Is he making eye contact with his corner staff? Was the fighter steady on his feet as he walked back to his corner at the end of the round? Does the fighter voice any problems to his corner staff, such as headache or pressure in head, dizziness, or blurred vision?). The ringside physician should attempt to do the above evaluations without obstructing or imposing on the corner's time with its fighter.

4. If the ringside physician determines that he/she needs more time to evaluate the neurological status of a fighter, he/she should communicate this to the referee. The referee, after starting the bout, shall call a time-out and walk the fighter to the ringside physician to be examined. The referee will then direct the other fighter to remain in the neutral corner. The ringside physician's goal at this time is to conduct a quick but thorough neurological assessment of the fighter. $\mathrm{He} / \mathrm{she}$ should begin this by asking the fighter a few leading questions, such as-How do you feel? Does your head hurt? Do you know where you are? If the fighter appears confused and disorientated, the ringside physician may ask more questions such as: Which round is this? Who is your opponent? Where are you fighting (the name of the venue)? The ringside physician should then look for pupil symmetry and response, and assess extraocular movements (have the fighter track a finger from side to side). The ringside physician should then give the fighter a complex command, such as Touch your left ear with your right glove. The physician should also assess the fighter's gait and balance at the same time (is the fighter steady on his/her feet or is he leaning on the ropes for support?). The ringside physician should then communicate to the referee whether the fighter can continue or that the fight be stopped. The whole process should not take more than 10 seconds.

5. The ringside physician should be aware that too much time spent evaluating the fighter during time-out, inadvertently gives the fighter more time to recover. The opponent's corner rightfully resents this as it is akin to being "saved by the bell". The public, TV audience, press and TV announcers question the fairness of the Commission's administration of the contest and the credibility and impartiality of the bout officials, e.g., referees, judges and ringside physicians.

6. If a serious health concern is raised for a fighter and the ringside physician is unable to document a good exam to determine whether it is safe for the fighter to continue, consideration should be given to stopping the fight. Under these circumstances the ringside physician should tell the referee that the fight be stopped on medical grounds.
7. For ringside physicians with limited ringside experience, it is encouraged that they consult with other ringside physicians at the venue and the Chief Medical Officer before the decision is taken to stop a fight on medical grounds.

As injuries mount, the boxing community is looking within itself and the sport is under scrutiny from the medical community and the media. Boxing is the most controversial sport for physicians and neurologists in particular because of the potential risk and degree of neurologic injury, questions and concerns about long-term sequelae (chronic traumatic encephalopathy), and the occurrence of deaths in the ring. ${ }^{[3]}$ Various medical associations including the American Medical Association and the American Academy of Paediatrics have stated opposition to both amateur and professional boxing. ${ }^{[4]}$ Many have called to ban boxing altogether. ${ }^{[5,6]}$ Dr. Hauser in a recent editorial titled "Beaten into action: a perspective on blood sports" said that "...the medical, and especially the neurology, community has an obligation to do more. We need to spread the word that brain bashing is not a socially acceptable spectator sport, and partner with our national organizations to expand and improve the effectiveness of public awareness and other educational initiatives." [7] He further goes on to state that "...we should forcefully counter articles in the medical literature taking the position that closer medical supervision could obviate the need for a ban, or even worse that consenting adults have the ethical right to maim each other if they choose to do so." [7] While the neurological risks of boxing cannot be completely eliminated, boxing can be made safer. ${ }^{[8,9]}$

\section{Conclusion}

It is recommended that the above proposed best practice guidelines be debated vigorously by ringside physicians and the wider scientific community and that evidence-based guidelines on medical stoppages be developed by the medical community in conjunction with the professional boxing governing bodies. Boxing can be made safer but it shall be foolhardy to forget that frequently there is a very fine line between a good medical stoppage (i.e. medical stoppage done at the right time during the bout and for the right indication) versus a bad medical stoppage (i.e. medical stoppage done either too late, too prematurely, or for the wrong indication). It is far better to stop a fight early rather than too late. A ringside physician should never forget that in boxing one punch can change everything.

Disclosure: The author serves as an Associate Editor, the Eastern Journal of Medicine and as Chief Medical Officer to the New York State Athletic Commission (NYSAC). The views expressed are his and do not represent the views of the NYSAC.

\section{References}

1. Association of Boxing Commissions. Uniform Rules of Boxing (approved August 25, 2001, Amended August 2, 2002, Amended July 3, 2008, Amended July 24, 2012, Amended July 29, 2014)

2. Baird LC, Newman CB, Volk H, et al. Mortality resulting from head injury in professional boxing. Neurosurgery 2010; 67:1444-1450; discussion 1450. [doi: 10.1227/NEU.0b013e3181e5e2cd] 
3. McCrory P, Zazryn T, Cameron P. The evidence for chronic traumatic encephalopathy in boxing. Sports Med 2007; 37(6):467-476. Review. [http://dx.doi.org/10.2165/00007256-200737060-00001]

4. Pearn J. Boxing, youth and children. J Paediatr Child Health 1998; 34(4):311-313. [http://dx.doi.org/10.1046/j.1440-1754.1998.00231.x]

5. Rudd S, Hodge J, Finley R, et al. Should we ban boxing? BMJ 2016; 352:i389. [http://dx.doi.org/10.1136/bmj.i389]

6. Hagell P. Should boxing be banned? J Neurosci Nurs 2000; 32(2):126128. [http://dx.doi.org/10.1097/01376517-200004000-00009]
7. Hauser SL. Beaten into action: a perspective on blood sports. Ann Neurol 2012; 72(3):A4-A5. [http://dx.doi.org/10.1002/ana.23743]

8. Gillon R. Doctors should not try to ban boxing--but boxing's own ethics suggests reform. J Med Ethics 1998; 24:3-4 [http://dx.doi.org/10.1136/jme.24.1.3]

9. Sethi NK. Boxing can be made safer. Ann Neurol 2013; 73(1):147 [http://dx.doi.org/10.1002/ana.23807] 